We thank Mr C J Davies and Mr S Luzio for technical help.

\section{References \\ 1 Buckley BM, Bold AM. Managing hyperlipidaemias. Br Med f 1982;285:1293-4 2 Schlant RC, Digirolamo M. Modification of risk factor in the prevention and management of coronary atherosclerotic heart disease. In: Hurst JW, Logue Hill Book Co, 1978:1311-44. \\ 3 Levy RI, Manning F. Risk factors for coronary artery disease and their manage- ment. In: Braunwald $\mathrm{E}$, ed. Heart disease, a textbook of cardiovascular medicine. Philadelphia: WB Saunders, $1980: 1246-78$ \\ 4 Lewis B. Disorders of plasma lipid transport. In: Scott RB, ed Price's text- book of the practice of medicine. 12th ed. Oxford: Oxford University Press, 1978:426-32 \\ Biorck G, Blomquist G, Sievers J. Cholesterol values in patients with myo- cardial infarction and in a normal control group. Acta Med Scand 1957;156: 493-7. \\ 6 Bjorntorp P, Malmcrona R. Serum cholesterol in patients with myocardial infarction in younger ages. Acta Med Scand 1960;168:151-5. \\ Dodds C, Mills GL. Influence of myocardial infarction on plasma-lipoprotein \\ concentration. Lancet $1959 ; \mathrm{i}: 160-3$.
$8 \mathrm{Kirkby} \mathrm{K}$. Disturbances in serum lipids and in their fatty acid composition following acute myocardial infarction. Acta Med Scand 1972;192:523-8. \\ Tibblin G, Cramer K. Serum lipids during the course of acute myocardial infarction and one year afterwards. Acta Med Scand 1963;174:451-5. \\ 10 Welin G. Serum cholesterol in myocardial infarction. Nord Med 1948;37:324-6. Fyfe T, Baxter RH, Cochran KM, Booth EM. Plasma lipid changes after myo- \\ 12 Avogaro A, Bittilo Bon G, Cazzalato C, et al. Variations in apolipoproteins B and}

A during the course of myocardial infarction. Eur $\mathcal{F}$ Clin Invest 1978;8:121-9. JP, Morrison BA, Ballantyne D. Response of plasma lipoproteins and acute phase proteins to myocardial infarction. 79:99:85-92.

14 Heldenburg D, Rubenstein A, Levtov O, Berns L, Werbin B, Tamir L. Serum lipids and lipoprotein concentrations during the acute phase of myocardial infarction. Atherosclerosis $1980 ; 35: 433-7$.

15 Keys A, Aravanis C, Blackburn H, et al. Probability of middle aged men developing coronary heart disease in five years. Circulation $1972 ; 45: 815-28$.

16 Pooling Project Research Group. Relationship of blood pressure, serum cholesterol, smoking habit, relative weight, and ECG abnormalities to incidence of major coronary events. Final report of the pooling project. $\mathcal{F}$ Chronic Dis $1978 ; 131: 201-306$

17 Heiss G, Johnson NJ, Reiland S, Davis CE, Tyroler HA. The epidemiology of plasma high density lipoprotein cholesterol levels. The Lipid Research Clinics Program prevalence study: summary. Circulation $1980 ; 62$ (suppl 4):116-36.

18 Gordon T, Castelli WP, Hyortland MC, Kannel WB, Dawber TR. High density lipoprotein as a protective factor against

19 Lipid Research Clinics Program. The lipid research clinics coronary primary prevention trial results: 1 . Reduction in incidence of coronary heart disease. PAMA 1984;251:351-64.

20 Lipid Research Clinics Program. The lipid research clinics coronary primary prevention trial results: 2 . The relationship of reduction in incidence of coronary heart disease to cholesterol lowering. $\mathcal{F A M A} 1984 ; 251: 365-74$

21 Rosenhamer G, Carlson LA. Effect of combined clofibrate-nicotinic acid treatment in ischaemic heart disease. Atherosclerosis $1980 ; 37: 129-38$

22 International Society and Federation of Cardiology Scientific Councils on Arteriosclerosis, Epidemiology and Prevention, and Rehabilitation. Join recommendations. Secondary

(Accepted 29 August 1984)

\title{
Fast neutron treatment as an alternative to radical surgery for malignant tumours of the facial area
}

\begin{abstract}
Thirty one patients with very advanced tumours of the maxillary sinus were treated with fast neutrons. Tumour regressed completely in $29(94 \%)$ and subsequently recurred in four $(14 \%)$. No surgical excision of bone, skin, or nerve was required, and an artificial eye was well tolerated in cases where the eye received the tumour dose and had to be removed. Complications occurred in 10 patients, two of whom had already received radical $x$ ray treatment. The overall duration of neutron treatment was four weeks, and admission to hospital was usually unnecessary. These results compared well with those obtained with surgery. Surgery with curative intent for even moderately advanced tumours of the facial region, particularly the paranasal sinuses, results in deformity, which is often severe and always irreversible. Even so, the cure rate is only about $35 \%$.

The high rates of tumour control and the avoidance of severe cosmetic and functional defects after fast neutron treatment make it an alternative to radical surgery in the management of malignant tumours of the facial area.

\footnotetext{
Fast Neutron Clinic, Medical Research Council Cyclotron Unit, Hammersmith Hospital, London W12 0HS

MARY CATTERALL, FRCR, DSC, consultant

P R BLAKE, FRCR, senior registrar

R P RAMPLING, MRCP, PHD, registrar

Correspondence to: Dr M Catterall.
}

\section{Introduction}

Coverage has recently been given in the national press and on television to a group of people whose aim is to give support to patients who have undergone radical surgery for the removal of tumours of the face. This has drawn attention to the plight of these patients, relatively few in number and rarely seen in public. Their disabilities result from removal of the entire bony orbit, maxilla, or facial nerve and from construction of forehead or chest skin flaps, leaving cosmetic results that often cause them severely to restrict their social lives. ${ }^{12}$ Skilfully designed prostheses, understanding relatives, and support groups all help to lessen the effects of this morbidity. Morbidity is, however, unalterable for the rest of their lives unless the tumour recurs, when even further surgery, phototherapy, or laser beam surgery may be undertaken.

Tumours of the paranasal sinuses are often advanced when the patients are first seen and the bone is often affected. Some are "radioresistant" because of hypoxia or some other biological property and they also have a great propensity to spread along nerves or tissue planes. ${ }^{3}$ These factors make their control by $Y$ and $x$ rays difficult because the high doses required to sterilise the tumour are beyond the tolerance of the adjacent normal tissues. Radiation damage to bone and nervous tissue often appears in addition to recurrence of tumour. Thus the management of these tumours usually consists of a combination of surgery and radiation. ${ }^{2}$

Fast neutrons have different biological effects from $x$ rays, and these differences result in therapeutic advantages in treating locally advanced or radioresistant tumour in certain sites. ${ }^{4}$ Neutrons are more effective against hypoxic malignant cells, and the damage they inflict is usually lethal rather than repairable as it often is after $x$ rays. Furthermore, neutrons are absorbed by tissues in proportion to the concentration of hydrogen atoms. Consequently, soft tissues, which include tumours, absorb relatively more neutron energy and suffer greater damage than does bone. As bone is a dose limiting 
tissue in conventional $x$ ray treatment, particularly in the facial region, neutron treatment in this area has advantages.

Neutron treatment has been carried out at this hospital since 1970. Ninety per cent of the patients treated in that time have had locally very advanced tumours or recurrences after $x$ ray treatment or surgery, or both. Local control rates of about $70 \%$ have been obtained in tumours of the head and neck, melanoma, and soft tissue sarcoma compared with rates of about $40 \%$ after $x$ ray treatment in tumours of the same stage. ${ }^{4-6}$ The cyclotron weeks. Patients were immobilised in "litecast" masks, and the treatment fields were reduced in size as the tumours regressed so that the normal tissues were spared radiation as much as possible while the tumour received the maximum dose. This regimen resulted in an appreciable erythema of the treated skin, which proceeded to moist desquamation followed by complete healing within two to four weeks after the end of treatment. There were no systemic effects, and admission to hospital was necessary only for those living at a great distance or suffering from some coexisting disease. In 11 cases the eye was encircled by tumour and was included in the high dose
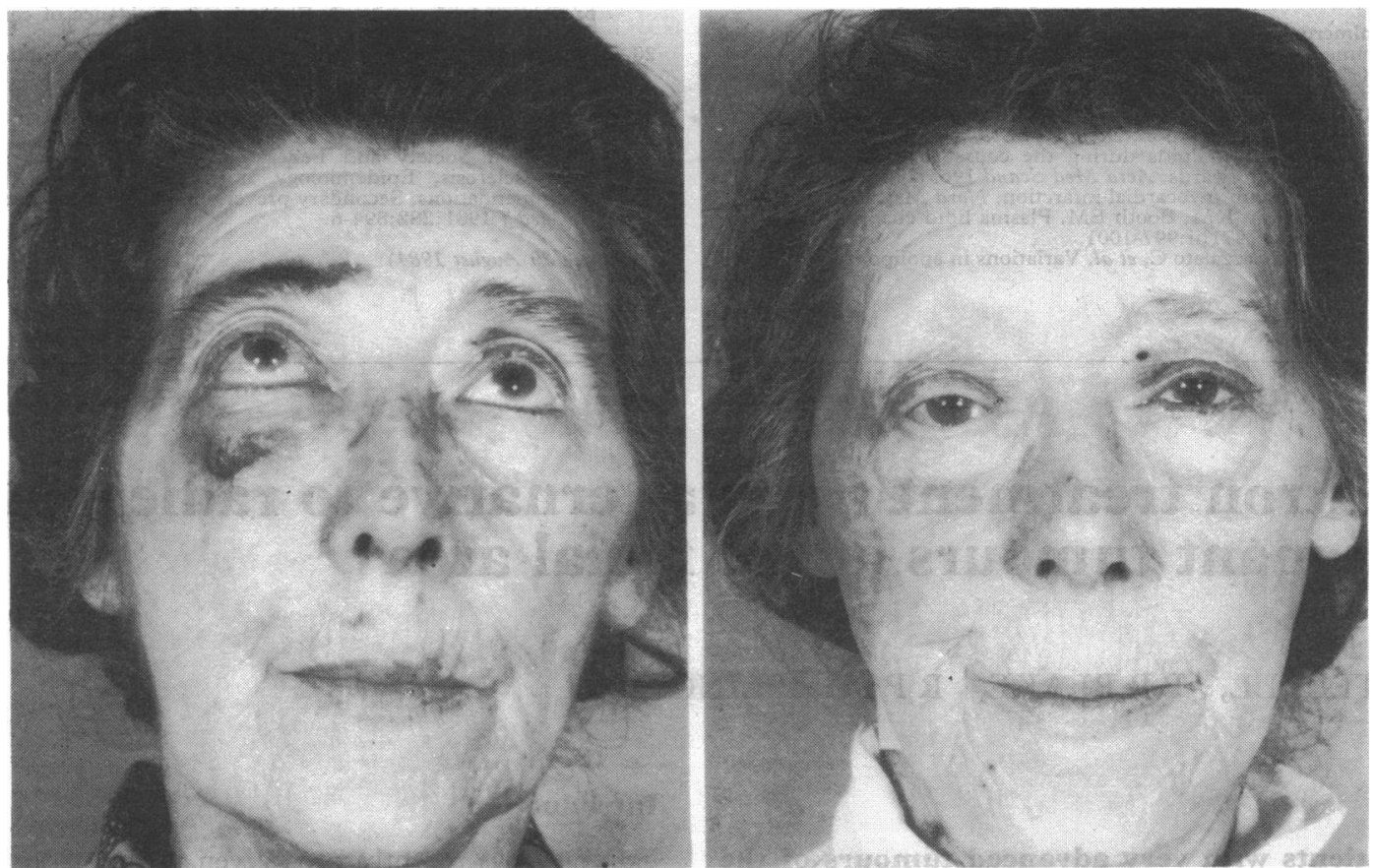

FIG 1-Patient with maxillary sinus tumour extending to skin, zygoma, nasal cavity, and orbit and causing proptosis before (left) and after (right) treatment with neutrons. After neutron treatment there was no sign of tumour and no proptosis. The eye was retained, and the patient lived for 10 years without recurrence.

is now 28 years old and has technical disadvantages including a mean energy of the neutron beam of only $7.5 \mathrm{MeV}$. This makes the beam less penetrating and more diffuse than megavoltage $x$ rays. In addition, the maximum dose is delivered to the skin, whereas the skin is spared radiation damage when modern $x$ ray treatment is used. Also the neutron beam is fixed in the horizontal position, which makes it more difficult to handle than $x$ ray beams, which rotate around the patient. Despite these difficulties the results show that neutrons control advanced tumours of the paranasal sinuses in a large proportion of cases and that the morbidity is less than after surgery. We report our results with this treatment and suggest that the avoidance of radical facial surgery is possible in some cases.

\section{Patients and methods}

Thirty one patients had locally advanced tumours of the maxillary sinus that were inoperable because of extension beyond the sinus or because the patient's general condition was poor. Six had tumours that had had recurred after radiotherapy or chemotherapy. In 20 of the 31 patients the tumour had extended to adjacent structures including one or more of the following: the ethmoid and sphenoid sinuses, orbit, nasal cavity, brain, skin, and neck nodes. In the remaining 11 patients at least two walls of the antrum were eroded on radiological examination. The table shows the histological types of tumour.

Treatment with fast neutrons was given by the techniques developed at this hospital. ${ }^{4}$ These include careful assessment of the tumour volume and meticulous planning of treatment to minimise damage to vital structures. Altogether $1560 \mathrm{cGy}$ (1560 rads) were delivered to the tumour, in 12 fractions equally spaced over four volume. It was known that this would cause damage to the eye, and this was explained to patients before treatment was started.

\section{Results}

All the tumours responded to neutron treatment with regression of the measurable mass and improvement in symptoms (table, fig 1).

Results of treatment with fast neutrons for advanced tumours of paranasal sinuses, related to histological type and previous treatment

\begin{tabular}{lclc}
\hline \multicolumn{1}{c}{ Histological type } & $\begin{array}{c}\text { No }(\%) \\
\text { regressing } \\
\text { completely }\end{array}$ & $\begin{array}{c}\text { No } \\
(\%) \\
\text { recurring }\end{array}$ & $\begin{array}{c}\text { No }(\%) \\
\text { with } \\
\text { complications }\end{array}$ \\
\hline $\begin{array}{l}\text { Adenocarcinoma }(n=7) \\
\text { Adenoid cystic }(n=6)\end{array}$ & 6 & 1 & 3 \\
Malignant melanoma $(n=1)$ & 6 & 1 & 3 \\
Squamous $(n=12)$ & 11 & 1 & 4 \\
Transitional cell $(n=5)$ & 5 & 1 & $40^{*}(32)$ \\
\hline Total $(n=31)$ & $29(94)$ & $4(14)$ &
\end{tabular}

* Three patients had received previous radiotherapy.

Complete regression of the tumour was achieved in $29(94 \%)$. Recurrence occurred in four, $75,26,17$, and six months after treatment. Median survival time was 36 months, with 10 patients still alive at the time of writing. Death was due to metastasis in seven, uncontrolled primary tumour in six, and causes either unknown or unrelated to cancer in eight.

Complications developed in 10 patients, three of whom had previously received full courses of radiotherapy. These complications 
affected the temporal lobe in five patients and caused fits in three, two of whom were controlled by steroids for the remainder of their lives (58 and 24 months). The third was still alive 44 months after neutron treatment and free of fits four months after treatment with steroids. In one patient, the abnormality of the temporal lobe produced no symptoms but was found on computed tomography and was treated prophylactically with steroids for five months. The oedema seen on computed tomograms was reduced within three months after treatment with steroids.

One patient suffered necrosis of the skin, infection of the fontal bone, and an abscess in the fontal lobe. This responded to antibiotics, and he lived for a further 20 months. Three other patients had necrosis of bone and skin; of them, two had received previous radiation with $\gamma$ rays and one chemotherapy.

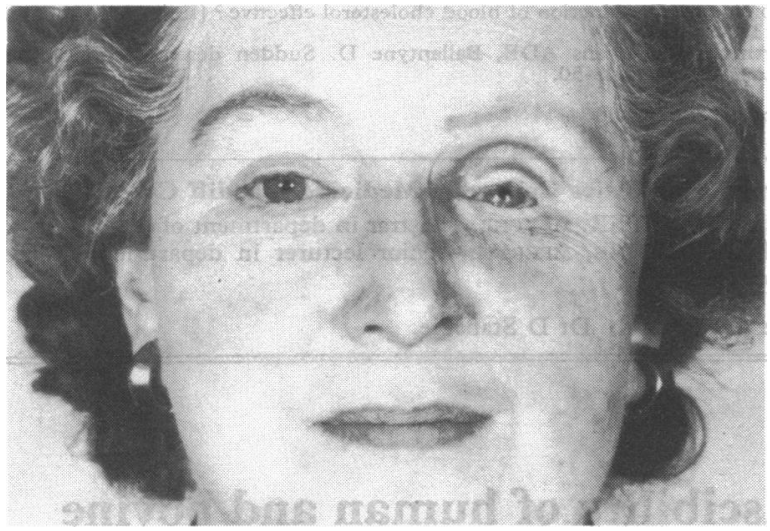

FIG 2-Patient with artificial eye fitted after neutron treatment for a tumour affecting maxillary and ethmoid sinuses, orbit, and nasa cavity necessitated removal of the globe. The evelids were fibrosed by the treatment but accepted the artificial eye without discomfort.

Of the 11 patients who received the full dose to the eye on the affected side, eight suffered a blind and painful eye 11-13 months after treatment. In seven the globe was removed. Four had an artificial eye fitted, which was well tolerated despite some fibrosis of the eyelids (fig 2); three patients declined an artificial eye but had no symptoms from the empty socket. One patient, whose tumour extended to the optic chiasma, became totally blind, either through radiation necrosis or through extension of the tumour; necropsy was not performed.

\section{Discussion}

Cancer of the maxillary sinus is often fatal, and cure rates at three years are of the order of $40 \%$ in the best series, whether by radiotherapy ${ }^{7}$ or combined surgery and radictherapy. ${ }^{2}$ These cancers produce severe disfigurement through ulceration of the skin and by affecting nerves and bone. Death from uncontrolled tumours can be appalling. In view of this, Harrison advised that the surgeon's responsibility is to clear the whole tumour bearing area as widely as possible despite the cosmetic and functional effects and to follow this by radiotherapy. ${ }^{2}$ In selected cases teams of three surgeons from the specialties of plastic, oral, and ear, nose, and throat surgery can undertake an extensive procedure, lasting nine to 10 hours, of excision and reconstruction. Even with such radical approaches the control rate is only $35 \%$.

Despite the very advanced stage of the tumours treated in our 31 patients neutron treatment controlled $25(80 \%)$, and the cosmetic and functional results were more acceptable than after surgery (fig 2). Survival was also longer after neutron treatment, but this may be considered to be of less importance than the cosmetic effects as if these are bad survival of any length can be miserable. Those patients whose survival is short, due either to the advanced stage of disease or to age, should not be con- fined to hospital for long periods. Management with combined surgery and radiotherapy is prolonged, extending over 12-14 weeks. Less radical surgery is being tried in selected cases, but recurrence remains a major threat and adequate follow up is required before changes can safely be made. Neutron treatment requires only 12 attendances over four weeks followed by four attendances over two to four weeks while the skin reaction heals.

Bataini and Ennuyer used high doses of megavoltage $x$ rays or electrons and obtained local cure at three years in 12 of 31 patients. Ten, possibly 18, tumours were not controlled locally. Most of their patients had extensive bone destruction but none of them had received previous radiation and none had tumour extending into the brain. In the series treated at this hospital the extent of the tumour was greater in most cases, in three tumour had recurred after $x$ ray treatment, and the tumour had extended into the frontal lobe in one.

Complications after neutron treatment were due in part to the extent of the tumours and their destruction of normal tissues and also to the inadequacy of our neutron beam. This is equivalent in many ways to only $250 \mathrm{kV} x$ rays, which became obsolete with the advent of the megavoltage apparatus. Three rather than two fields may be required; thus normal tissues receive a higher dose than is desirable despite the development of elaborate techniques to minimise this. Neutrons from modern cyclotrons will have an energy of $25 \mathrm{MeV}$ rather than $7.5 \mathrm{MeV}$ and the beams will be better defined and more penetrating. Complications will therefore be reduced.

The table shows that the results of treatment are equally good for all histological types of tumour. This is an important characteristic of neutron treatment and has been noted for advanced tumours in all sites where an adequate dose of neutrons can be delivered. ${ }^{4}{ }^{5}$ It reflects the greater efficacy of neutrons over $x$ rays in the treatment of tumours in which the cells are hypoxic or radioresistant for some other biological reason.

Complete regression rates of about $90 \%$ and recurrence rates of $14 \%$ after neutron treatment were obtained in our series even for very advanced tumours of the maxillary sinus; only six of our patients died with an uncontrolled primary tumour. These results compare favourably with others that have been published but would be more impressive if they were from a controlled clinical trial. With an annual incidence, however, of about 500 cases throughout England and Wales the difficulties of randomising cases of the same stage and prognosis to treatment with neutrons or to conventional radiotherapy with or without surgery would be great. In addition, some patients already decline radical surgery and others might also if neutrons were available as an alternative treatment and informed consent was sought before randomisation.

The results reported in this paper were obtained with the first ever medical cyclotron, which has major deficiencies. With the high energy neutrons now available from modern machines recurrence and complications are likely to be less than those we report. The high incidence of local control, together with avoidance of major facial surgery, makes neutron treatment an alternative method for managing these dangerous and disfiguring tumours.

\section{References}

1 Corcoran MO, Cook HP, Hobsley M. Radical surgery following radiotherapy for advanced parotid carcinoma. Br $\mathcal{F}$ Surg 1983;70:261-3.

Harrison DFN. The management of malignant tumours affecting the maxillary and ethmoidal sinuses. $\mathcal{F}$ Laryngol Otol 1973;87:749-72.

Moron. JJ, Becker SM, Brady LW, Rambo VB. Adenoid cystic carcinoma: a clinico-pathological study. Cancer $1961 ; 14: 1235-50$.

atterall M, Bewley DK. Fast neutrons in the treatment of cancer. London:

5 Rampling RP, Catterall M. Facial nerve damage in the treatment of tumours of the parotid gland. Fournal of Clinical Oncology (in press)

6 Laramore GE, Griffin TW. Potential application of a clinical neutron beam generator in cancer management. Applied Radiology (in press).

Bataini JP, Ennuyer A. Advanced carcinoma of the maxillary antrum treated by cobalt teletherapy and electron beam irradiation. Br $\mathcal{F}$ Radiol 1971;44:590-8.

(Accepted 26 September 1984)

,

으 